\title{
Emergence patterns in tropical insects: the role of water discharge frequency in an Andean Stream
}

\author{
Maria I. Castro-Rebolledo ${ }^{1}$ and Jhon Ch. Donato-Rondon ${ }^{2 *}$ \\ 1 Department of Biology, Universidad Nacional de Colombia, Ave (Cra. 30) No. 45-03, Bogotá, Colombia \\ 2 Department of Biology, Universidad Nacional de Colombia, Ave (Cra. 30) No. 45-03, Bogotá, Colombia
}

Received 21 July 2014; Accepted 4 March 2015

\begin{abstract}
The aim of this study was to examine the relationship between the emergence patterns of various groups of aquatic insects and different hydrological discharge periods. We hypothesize that hydrological fluctuations exert a strong influence on insect emergence, even though the orders show different responses to discharge frequency. The emergence of Diptera, Trichoptera and Ephemeroptera was measured in a tropical stream with a mesh emergence net. The sampling took place every 2 days for 14 months. Based on water flow records taken throughout the sampling period nine discharge categories were defined. A significant relationship between macroinvertebrate emergence and discharge was found, and a high percentage of emergences was fundamentally concentrated within two discharge categories namely $<0.352 \mathrm{~m}^{3} . \mathrm{s}^{-1}$ and $0.352-0.579 \mathrm{~m}^{3} \cdot \mathrm{s}^{-1}$. We used a time series consisting of 60 weekly samples to describe how emergence varied in an intra-annual period. Autoregressive integrated moving average (ARIMA) models were applied to analyze the time series of data collected for macroinvertebrate order. Time-series models for Trichoptera and Ephemeroptera showed a lagging relationship between the moving average (MA) of the emergences and environmental and biological factors, which occurred one (MAI) and two (MAII) periods earlier, respectively. For Diptera, a relationship was found between emergence and discharge for the autoregressive (AR) order. The relationship was regulated by the autecology of the organisms and occurred AR two time periods earlier (AR2). This study showed that the response of macroinvertebrates to discharge can be differentiated and can produce relevant changes in biodiversity.
\end{abstract}

Key words: Emergence / Diptera / Trichoptera / Ephemeroptera / time series / tropical stream

\section{Introduction}

Fluvial systems contain a small percentage of the world's fresh water. They are an important part of the hydrological cycle because they annually transport 32-37 $\mathrm{km}^{3} \mathrm{yr}^{-1}$ of water to the oceans (Schlesinger, 2000). Moreover, small rivers, because they represent $90 \%$ of the surface area of the drainage network, have extraordinary importance in global biochemistry and in the preservation of biodiversity (Sabater, 2008). Anthropogenic impacts on river hydrology and climate change affect water flow, riverbed geomorphology and the self-organization processes of the ecosystem. As a consequence, these impacts can produce a loss of biodiversity and generate trophic simplification of the rivers. For example, when air temperature increases and precipitation patterns change, many studies predict an increase in the intensity and frequency of extreme flow events in fluvial systems,

\footnotetext{
*Correspondence author: jcdonator@unal.edu.co
}

such as floods and drought (Harper and Peckarsky, 2006). However, these impacts are not well understood at the regional level in some areas, especially in high-altitude Andean rivers and streams, where variations in water temperature are minimal and differences between the periods are mostly determined by hydrology (Lewis, 2008).

Compared with temperate river systems, the Andean tropical fluvial ecosystems host a wealth of biological diversity. High mountain tropical streams have small variations in water temperature, but large variations in water flow throughout the year. Rainy periods that produce high water flow alternate with drier periods which produce basal flow. (Donato et al., 2014). These events not only have an effect on ecosystem characteristics, but also on the structure and dynamics of biological communities. For example, the intensity of spates during the rainy period is associated with rainfall frequency and local topography, and may affect stability, turbidity and mobility of streambed substrata (Jacobsen, 2005, 2008). During these 
periods, high discharge can limit emergence patterns (Flint and Masteller, 1993).

The emergence of insects is a measure of stream productivity and, therefore, is a reliable indicator of secondary production in fluvial systems (Statzner and Resh, 1993). Benthic insect production can be divided into two major groups: one that spends its entire life in the water as part of the benthic food web and the other that leaves the water as emerging insects (Poepperl, 2000). Emergence is the transitional period of the life cycle between the aquatic nymph and adult stages. It represents the culmination of insect productivity in aquatic environments and is a potential source of energy and nutrient transfer from aquatic to terrestrial environments (Whiles and Goldowitz, 2001). Additionally, emergence is a critical period in the life cycle of the adult insects, because movement to the water's surface in the daytime makes them vulnerable to aquatic and aerial predators. Latitudinal and altitudinal factors have been shown to play an important role in emergence and to influence the duration of emergence periods. Temperate streams have been shown to exhibit a seasonal variation in adult emergence from winter to autumn, while for tropical streams the emergence of some groups (e.g., Chironomids) is continuous (Coffman and de la Rosa, 1998). In the tropics and in temperate regions, air temperatures are not very restrictive. As a result, most species emerge during the first $2 \mathrm{~h}$ of the night to avoid predators that could catch them in daylight (Huhta et al., 2000). The photoperiod is a potential factor regulating the seasonal emergence of Ephemeroptera, as are humidity, wind, precipitation, turbidity and irradiance (Brittain, 1982). In rivers in temperate areas, factors associated with water deficiency, which affects either water temperature or basal river flow, can affect the emergence of adults insects (Peckarsky et al., 2001).

Temporal emergence patterns (continuous, rhythmic, sporadic and seasonal) are explained both by proximate factors, which regulate the emergence rate and correspond to short-term responses, and ultimate factors, which exert control through natural selection (Corbet, 2004). Although emergence is generally considered an important ecological process and the continuous study of the emergence of aquatic insect larvae is related to biological production, few intensive studies of emergence have been conducted (Statzner and Resh, 1993). The phenological data of aquatic insect species for the tropical lotic systems are scarce, which might explain why our knowledge about species richness and phenological patterns for these groups is still obscure (Coffman and de la Rosa, 1998).This is particularly the case for neotropical streams.

The aim of this study was to examine the emergence abundance and emergence phenology of Ephemeroptera, Diptera and Trichoptera (ETD) through an intensive study. We hypothesized that hydrological fluctuations exert a strong influence on insect emergence, even though the species show different responses to water flow frequency. We also characterized and modeled emergence patterns in a third-order high-altitude stream in the
Colombian Andes using autoregressive integrated moving average models (ARIMA).

\section{Methods}

\section{Study area}

In Colombia, intertropical confluence defines a general weather pattern as it passes through the country twice a year. Firstly, between April and May, which corresponds to the rainy season, maximum temperatures decrease and minimum temperatures increase, resulting in an overall decrease in mean temperature. Secondly, between September and October, when temperatures decrease from the maximum temperature registered between July and August, a second, stronger rainy season begins, in which maximum temperatures decrease and minimum temperatures increase, resulting in an overall decrease in mean temperature (IDEAM, 1998). This behavior in rainfall explains the bimodal discharge pattern exhibited by the Tota Stream.

The study was conducted in the third-order of the Tota Stream $\left(5^{\circ} 36^{\prime} 43^{\prime \prime} \mathrm{LN} 72^{\circ} 58^{\prime} 45^{\prime \prime} \mathrm{LW}, 2560 \mathrm{~m}\right.$ a.s.1). During the observation period, the study area had a bimodal rain regime with two rainy periods: the first from April $(97.6 \mathrm{~mm})$ to May $(87.4 \mathrm{~mm})$ and the second from October $(86.1 \mathrm{~mm})$ to November $(76.7 \mathrm{~mm})$. The period with the lowest precipitation was that from December $(26.2 \mathrm{~mm})$ to January $(13.8 \mathrm{~mm})$. Air temperature oscillated between $10.7^{\circ} \mathrm{C}$ (July-August 1997) and $13.1^{\circ} \mathrm{C}$ (February 1998), with an average temperature of $11.5^{\circ} \mathrm{C}$ between February and June, 1997.

According to Buitrago et al. (1987), there was a period of high sedimentation in rivers and lakes in the upper Pleistocene that culminated in the formation of the new Iza Valley. This valley was formed by the erosion of the Tota and Pesca Streams, which converge at the Chiquito River. The streambed was composed of rocks, cobbles, boulders and some deposits of sand and detritus. Though litter-fall is rather constant throughout the year, detritus accumulates only during periods of low flow (Donato et al., 2014).

The vegetation in this area is mainly composed of alder (Alnus acuminata), willow (Salix humboldtiana) and eucalyptus (Eucalyptus globulus). Currently, the land is used as pastures for cattle (IGAC, 1980).

Tota stream is not far from densely occupied areas in the Colombian Andes which have undergone environmental transformation: urban expansion, agricultural production, changes in land-use and fragmentation of production-units are characteristic processes affecting this stream basin.

\section{Sampling of macroinvertebrates}

Sampling was conducted on alternate days for 14 months. Emergence samples were collected on rocky substrates (randomly placed) with a $2.52 \mathrm{~m}^{-2}$ emergence 
mesh which was a modified version of that used by Merritt and Cummins (1995). To prevent substrate disturbance by the researcher, organisms were picked from the mesh after it had been removed from the water. Using a manual aspirator, we collected the individual specimens located on the bottom of the mesh. Collected specimens (imagoes and subimagoes) were preserved in $70 \%$ alcohol. At the same time, to confirm the taxonomic identification of adults (Ephemeroptera -E-, Trichoptera -T- and Diptera -D-), ETD larvae were collected using six artificial substrates. Three of these substrates were located in a fast current area and three in slow current areas. ETD organisms were identified using regional keys for larvae and adults (Domínguez and Fernández, 2009). Ephemeroptera and Trichoptera were identified to the genus level. Where this was not possible, their morphotypes were identified. Diptera were identified mainly to the family level.

\section{Environmental variables}

Based on the records of the limnimetric station of the Colombian Institute for Hydrology, Meteorology and Environmental Studies (IDEAM) located $500 \mathrm{~m}$ downstream from the sample point; discharge categories were defined using the monthly water-flow records from February 1997 to March 1998. Frequency ranges were determined by taking into account established intensity ranges and then determining how common the frequency ranges were in the system. For this purpose, each discharge was categorized. The discharges were ranged from 1 (minimum) to 9 (maximum), and included all discharge data from the lowest to the highest value. We also measured $\mathrm{pH}$ with a C-818 SCHOTT Gerade, temperature and dissolved oxygen with a YSI model 57, conductivity with a YSI model 33, soluble reactive phosphorus (SRP) and ammonium according with APHA (1998).

\section{Analysis and data interpretation}

Statistical techniques for time-series analysis are among the most widely used predictive methodologies in ecology. Among these are the ARIMA models, introduced by Box and Jenkins (1976), which enable the modeling of real phenomena. With these models, it is possible to estimate the pattern of temporal behavior of variables of interest and to make predictions based on these variables.

\section{Autoregressive integrated moving average models}

To analyze the series of daily samples by orders of ETD, ARIMA models were used. Daily abundance data were collected between February 1997 and March 1998. Additionally, data were treated as a temporal series of daily and weekly abundances.

Initially, ARIMA models were applied to stationary series; that is, to time-series with a constant mean and variance. The general form of the stationary ARIMA models was as follows:

$$
\begin{gathered}
\text { ARIMA }(p, \mathrm{~d}, q)(P, D, Q)^{n} \\
O_{p}(L) f_{p}\left(L^{s}\right)\left(1-L^{s}\right)^{\mathrm{D}} Y_{\mathrm{t}}=q_{\mathrm{q}}(L) q_{\mathrm{Q}}\left(L^{\mathrm{s}}\right)_{\varepsilon}
\end{gathered}
$$

where $Y_{t}$ is the value at time $t ;(1-L) \mathrm{d}$ is the stationary differentiation of order $D ;\left(1-L^{s}\right)^{\mathrm{D}}$ represents stationary differentiation of order $D ; q_{q}(L)$ and $q_{Q}(L)$ are the lagged polynomials of $L$ of the orders $p$ and $q$, respectively; $f_{p}\left(L^{s}\right)$ and $q_{Q}\left(L^{s}\right)$ are the lagged polynomials of $L^{s}$ of the orders $P$ and $Q$, respectively; $\varepsilon$ is the error term in time $t ; p$ is the order of the autoregressive (AR) term; $\mathrm{d}$ is the degree of differentiation needed to reach stationary; $q$ is the order of the moving average (MA) term; $s$ is the stationary period; $L$ is a lag operator that, applied to a variable $Y_{t}\left(L^{a} Y_{t}\right)$, lags it by periods $\left(Y_{t-a}\right)$; and $P, D$ and $Q$ are the stationary terms.

The design and fit of the ARIMA model was conducted in three successive stages: identification, construction and diagnosis (Box and Jenkins 1976). Once the stationary of the series was achieved, the identification stage of the model was based upon the analysis of the original data series by examining the simple autocorrelation function $(\mathrm{SACF})$ and the partial autocorrelation function (PACF). In the first phase, it was determined whether to apply a Box-Cox transformation to the series to achieve constant variance or whether to apply a differential to stabilize the mean.

The construction phase consisted of identifying the $\mathrm{AR}$ and MA structures and estimating and evaluating the significance of the parameters. To determine the model's values of $p$ and $q$ (of the orders $P$ and $Q$ respectively), the SACF and PACF of the both differential series and the transformed series were analyzed. To estimate model parameters, the non-linear parameter MARQUARDT was used, following the "backforecasting" method with a longer duration than the stationary of the series. This estimation procedure was used because it yields predictions with a better approximation to a continuous function. Once the parameters were estimated, they were analyzed with Student's t-test.

In the diagnosis phase, the residuals of the SACF and PACF were analyzed and tested for the normality of the residuals. Additionally, the cumulative periodogram of the residuals within the 5 and $25 \%$ limits were examined. This statistic, which is distributed asymptotically as an $\chi^{2}$ with $n$ degrees of freedom, allowed for a global contrast of the residuals and for the determination of whether these were white noise. The Lung-Box test was conducted to verify whether any of the residuals were different from zero.

\section{Results}

To measure the effect of water flow on emergence, we analyzed the water discharges recorded during the sample period from the IDEAM limnimetric station. A histogram of these data was used to define the following 


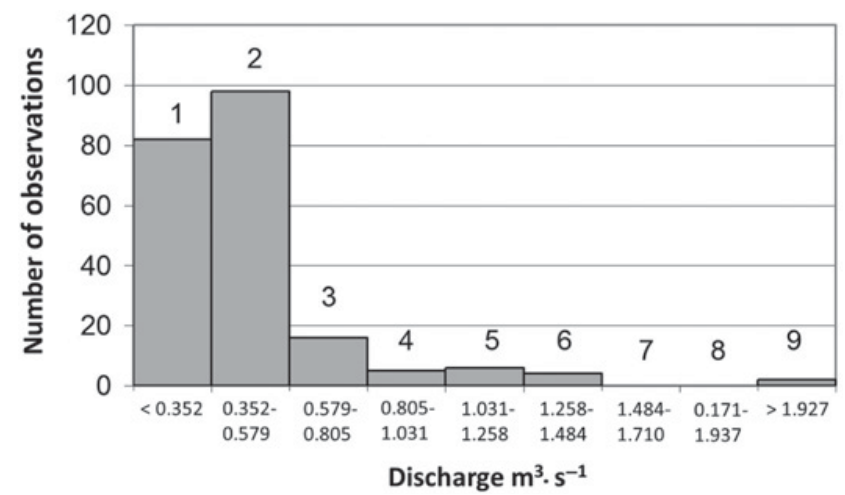

Fig. 1. Frequency histogram of the mean values of discharge $\left(\mathrm{m}^{3} \mathrm{~s}^{-1}\right)$ during the study period. The histogram bars correspond to the discharge categories.

water discharge categories: between 0 and $0.352 \mathrm{~m}^{3} . \mathrm{s}^{-1}$ (category 1,82 records); 0.352 and $0.579 \mathrm{~m}^{3} . \mathrm{s}^{-1}$ (category 2, 98 records); 0.579 and $0.805 \mathrm{~m}^{3} \cdot \mathrm{s}^{-1}$ (category 3 , 16 records); 0.805 and $1.031 \mathrm{~m}^{3} . \mathrm{s}^{-1}$ (category 4, 15 records); 1.031 and $1.258 \mathrm{~m}^{3} . \mathrm{s}^{-1}$ (category 5,6 records); 1.258 and $1.484 \mathrm{~m}^{3} \cdot \mathrm{s}^{-1}$ (category 6,4 records); 1.484 and $1.71 \mathrm{~m}^{3} . \mathrm{s}^{-1}$ (category 7, 0 record); 1.71 and $1.937 \mathrm{~m}^{3} \cdot \mathrm{s}^{-1}$ (category 8, 0 records); and $>1.937 \mathrm{~m}^{3} . \mathrm{s}^{-1}$ (category 9 , 2 records) (Fig. 1). The histogram was used to conclude that there are asymmetries in water discharge and that low discharge predominated. The median flow was more representative than the mean flow.

For the study area, the highest average discharges were recorded between the months of July and August $\left(1.097 \mathrm{~m}^{-3} \cdot \mathrm{s}^{-1}\right.$ and $0.646 \mathrm{~m}^{-3} \cdot \mathrm{s}^{-1}$, respectively), while the lower ones occurred from February to April 1997 $\left(0.291,0.272\right.$ and $0.282 \mathrm{~m}^{-3} \cdot \mathrm{s}^{-1}$, respectively). The months of September-December 1997 had an average of $0.444 \mathrm{~m}^{-3} \cdot \mathrm{s}^{-1}$, approximately.

The water conductivity increased during the months with the least rain. February 1998 was the month with the highest conductivity $\left(350 \mu \mathrm{Scm}^{-2}\right.$ at $25^{\circ} \mathrm{C}$ ), while July 1997 and August 1997 were the months the lowest conductivity $\left(95 \mu \mathrm{Scm}^{-2}\right.$ at $\left.25^{\circ} \mathrm{C}\right)$. The latter conductivity corresponded to the months with the highest rainfall, and represented the major change in this variable in the study period (coefficient of variation, $\mathrm{CV}=40,60 \%$ ). The water temperature ranged between 12.5 and $16{ }^{\circ} \mathrm{C}$ and the $\mathrm{CV}$ was $8.38 \%$. The months with the highest temperature records were those between February 1997 and May 1997 and those between November 1997 and February 1998. The month with the lowest temperature was September $1997\left(12.5^{\circ} \mathrm{C}\right)$. However, other months also had low temperatures, such as June $1997\left(13.5^{\circ} \mathrm{C}\right)$ and October $1997\left(13.6^{\circ} \mathrm{C}\right)$.

The SRP value ranged between $1.05 \mu \mathrm{mol} . \mathrm{L}^{-1}$ (May and September 1997, November and December 1997 and February 1998) and $5.05 \mu \mathrm{mol} . \mathrm{L}^{-1}$ (February 1997). The CV was $79.09 \%$, and the average was $1.73 \mu$ mol. $\mathrm{L}^{-1}$, changes which are associated with the rainy months. There was also an inverse relationship between ammonium concentration and the discharge in rainy periods. While the minimum concentrations were recorded in the months characterized by high precipitation, those from April $1997\left(11.09 \mu \mathrm{mol} . \mathrm{L}^{-1}\right)$ to October 1997 (8.32 $\left.\mu \mathrm{mol} . \mathrm{L}^{-1}\right)$, the highest concentrations were found in months with the lowest precipitation, namely December 1997 (38.81 umol.L ${ }^{-1}$ ) and January 1998 (33.26 $\left.\mu \mathrm{mol} . \mathrm{L}^{-1}\right)$. The $\mathrm{CV}$ was $89.87 \%$, and the average was $16.29 \mu \mathrm{mol} . \mathrm{L}^{-1}$. The average dissolved oxygen was $7.45 \mathrm{mg} . \mathrm{L}^{-1}$, the range being between $6.1 \mathrm{mg} . \mathrm{L}^{-1}$ (March 1997) and $9.55 \mathrm{mg} . \mathrm{L}^{-1}$ (September 1997). The CV was $13.43 \%$; the highest values were recorded in the period of greatest stream discharge.

\section{General emergence records}

\section{Diptera}

With an emergence average of 688.12 org. $\mathrm{m}^{-1}$ and a coefficient of variation of $78.65 \%$, the order Diptera was the most abundant in the study area. In total, 9638 organisms were collected, which primarily belonged to the families Simuliidae and Chironomidae. The highest monthly emergence was in February 1997 (1622 organisms), March 1997 (1144 organisms) and May 1997 (1563 organisms). The lowest values recorded were in August 1997 with 108 organisms and December 1997 with 100 organisms (Fig. 2). Simulium spp., were the most abundant during the rainy season and Chironomidae the most abundant species in the dry season.

\section{Trichoptera}

A total of 520 organisms emerged (Fig. 3), predominately members of the families Hydroptilidae (Hydroptila constricta, Metrichia sp.) and Glossosomatidae (Mexitrichia sp.). The months with the lowest emergences were July 1997, August 1997, November 1997, February 1998 and March 1998 each of which had only four individuals. Months such as December 1997 (13 organisms) and January 1998 (11 organisms) showed relatively higher emergence. The average emergence was 37 org. $\mathrm{m}^{-1}$.

\section{Ephemeroptera}

A total of 825 org. (Fig. 4) belonging to the families Baetidae (Paracloeodes spp. and Camelobaetidius spp.), Leptohyphidae (Thricorythodes sp.) and Leptophlebiidae (Thraulodes sp.) emerged. The average emergence was 58 org. $\mathrm{m}^{-1}$, while the coefficient of variation was $121.29 \%$. The month with the highest emergence was February 1997 (275 org.), followed by November 1997 (106 org.). In months such as April 1997 and June 1997, 72 and 70 org. emerged, respectively. In May 1997 and October 1997. 85 org. emerged. The months with the least emergence were February 1998 (1 org.) and May 1998 (no emergence). 


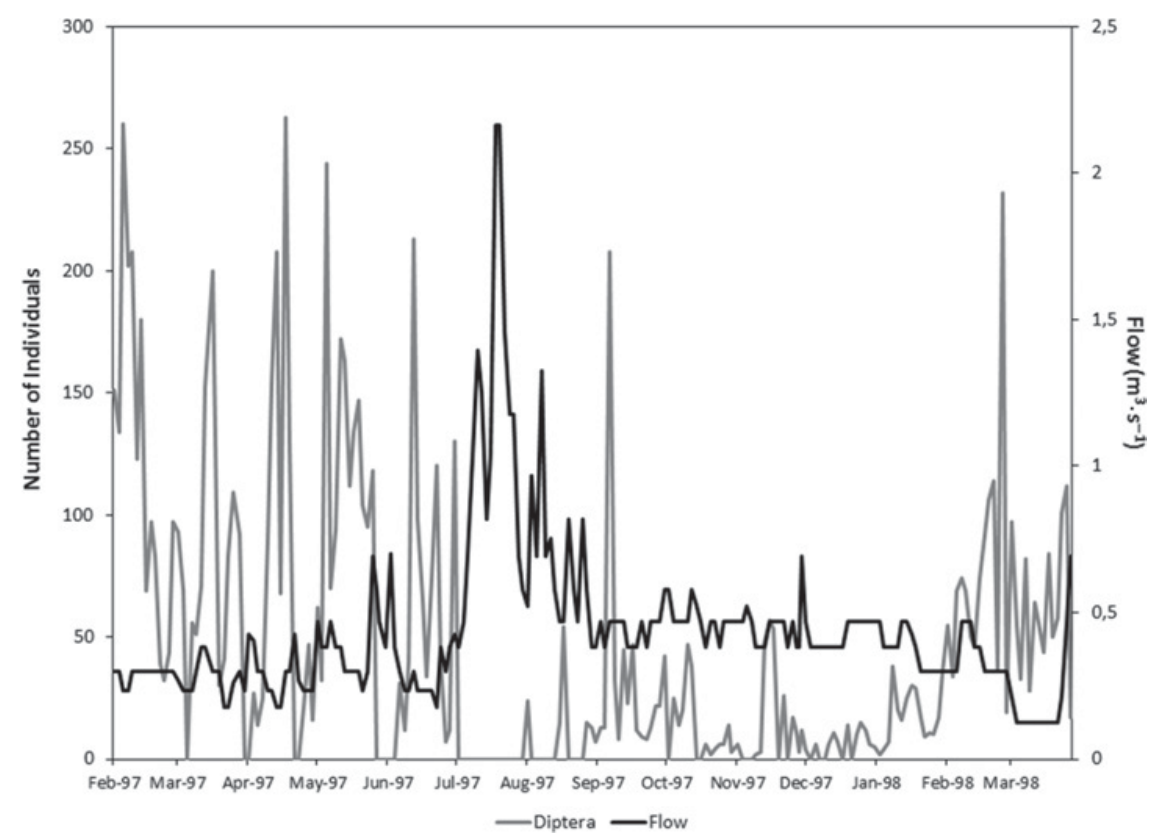

Fig. 2. Daily emergence of Diptera and its relationship to discharge in the study area.

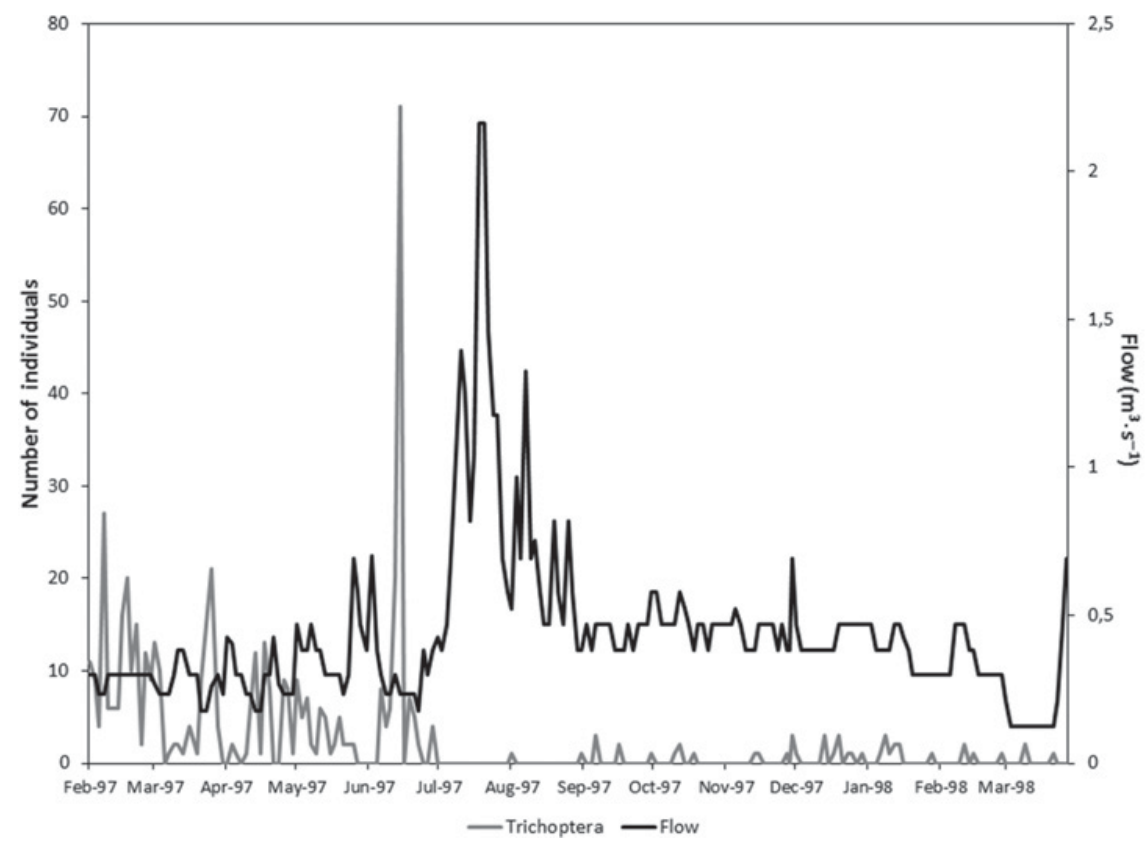

Fig. 3. Daily emergence of Trichoptera and its relationship to discharge in the study area.

\section{Autoregressive integrates moving average models}

The ARIMA was carried out for the genus, family and order levels. Tendencies suitable for analysis were found only at the order level and in the weekly emergence data.

\section{AR model for Diptera (AR2)}

The standard error and the results of Student's t-test established that the parameters estimated for the $\operatorname{AR}(2)$ model are significantly different from each other
$(P<0.0005)$. The PACF of the residuals (Fig. 5(a)) and the results of Kolmogorov-Smirnov normality test for the residuals indicate that the model is adequate. Therefore, once the autocorrelation function (ACF) (Fig. 5(b)) was calculated for the residuals, the autocorrelations were not significant $(P>0.05)$. Moreover, $P>0.05$ indicates that all of the deterministic information in the model was extracted from the series, which means that the residuals are normalized, and, therefore, the AR(2) model appropriately represents the data. From an ecological point of view, the $\operatorname{AR}(2)$ model indicates (1) that each observation of Diptera emergence is related to a Diptera emergence 


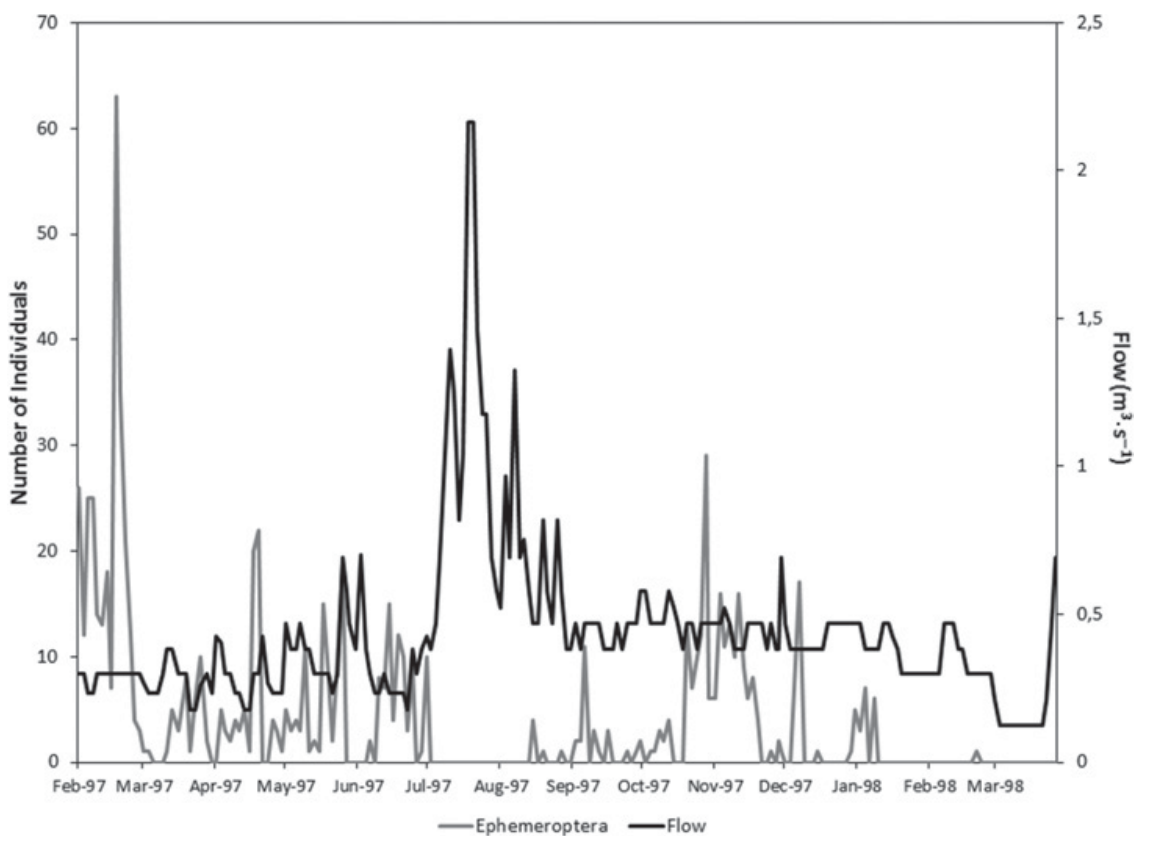

Fig. 4. Daily emergence of Ephemeroptera and its relationship to discharge in the study area.

before it and (2) that there is a two-period lag between each observation.

\section{MA model MA(I) to predict the emergence of Trichoptera}

In contrast to Diptera emergence, Trichoptera emergence was maximal during the first weeks of the study and very low in the final weeks of the study.

According to Fig. 6(a) and (b), ACF slowly declines and PACF abruptly declines to zero after the first period. The values of $P_{k}$ and $q$, and Student's $t$-test, show that the parameters estimated for MA(I) are significant $(P<0.0001)$. The MA(I) model represents a series in which the data are strongly interrelated and the observed values are generated by random fluctuations $\left(A_{1}\right)$ that occurred during a single time period (1 week).

\section{MA model to predict Ephemeroptera emergence}

On week 25 and between weeks 53 and 61, no emergence was recorded. No stationary order $D$ of differentiation exists in the series defined by the emergence data. The differentiation was performed and the results for ACF and PACF are shown in Fig. 7(a) and (b). When we compared the distribution of the autocorrelation using the historic series data, this distribution did not fit with the setting parameters (stationary series, bounded variance, normality of residuals) of the different models we tried.

In general, the correlation coefficients of the PACF correlation slowly decreased to zero, while those of the ACF decreased abruptly. These findings, together with the significance of the coefficients $(P<0.00025)$, were used to develop a model, MA(II). To test whether the model was adequate, the ACF for the residuals was calculated. This revealed that the autocorrelations were not significant $(P>0.05)$. Similar to the Trichoptera model, the Ephemeroptera model indicates a series with interrelated data generated by random fluctuations. However, in this case, the fluctuations occurred two periods earlier.

\section{Water flow categories versus the emergence}

\section{Diptera}

The highest emergences occurred in the two slowest discharge categories, 1 and 2. After the maximum rainpeak, some periods of regular emergence occurred in categories 3 and 4 , even though they did not reach the maximum emergence recorded for the first two categories.

\section{Trichoptera}

The emergence of most species occurred mainly in the first two categories of discharge. Only a few individual species emerged sporadically in category 5 (four individuals). In the first discharge category, a total of 402 individuals were recorded. In the second category, 86 individuals emerged. The higher emergence in the first categories showed that Trichoptera responded positively to low speeds of water flow.

\section{Ephemeroptera}

The emergence occurred in waters with the first four categories of discharge. In the first category, a total of 483 individuals emerged. In the second and third categories, 326 individuals and 20 emerged, respectively. 

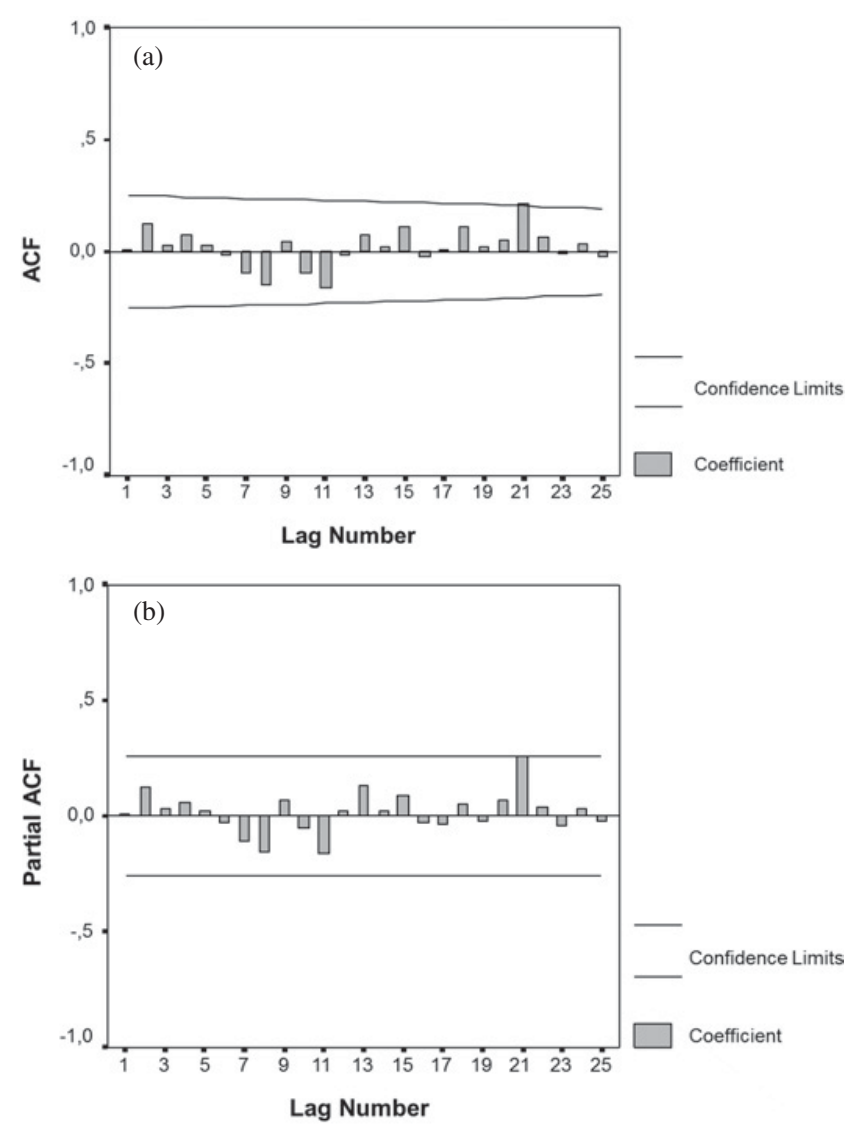

Fig. 5. (a) Simple autocorrelation of the residuals for the mean emergence of Diptera. (b) Partial autocorrelation of the residuals for the mean emergence of Diptera.

Finally, in the fourth category, only one individual emerged.

\section{Discussion}

In temperate areas, the dynamics of aquatic insect populations are easily determined by fluctuations in water temperature and day length. In any case, the emergence frequency tends to increase with water temperature(Wolf et al., 1988) and with longer periods of sunlight (Ivković et al., 2013). Patterns of emergence for organisms in tropical areas are harder to elucidate due to the weather stability in the tropics. However, even in thermally stable tropical regions, fluctuations in other environmental variables (such as photoperiod, rainfall and water flow) may be used as indicators of when emergence may occur (Siqueira et al., 2008).

However, we found that emergence (ETD) was related to physical factors, such as water flow, which experienced seasonal restrictions and therefore exhibited different responses in insect emergence. From an ecological viewpoint, Diptera emergence was related to the time series model AR(2), which indicates that each observation is related to the previous one and is separated by two time periods (15 days). Therefore, Diptera emergence generally
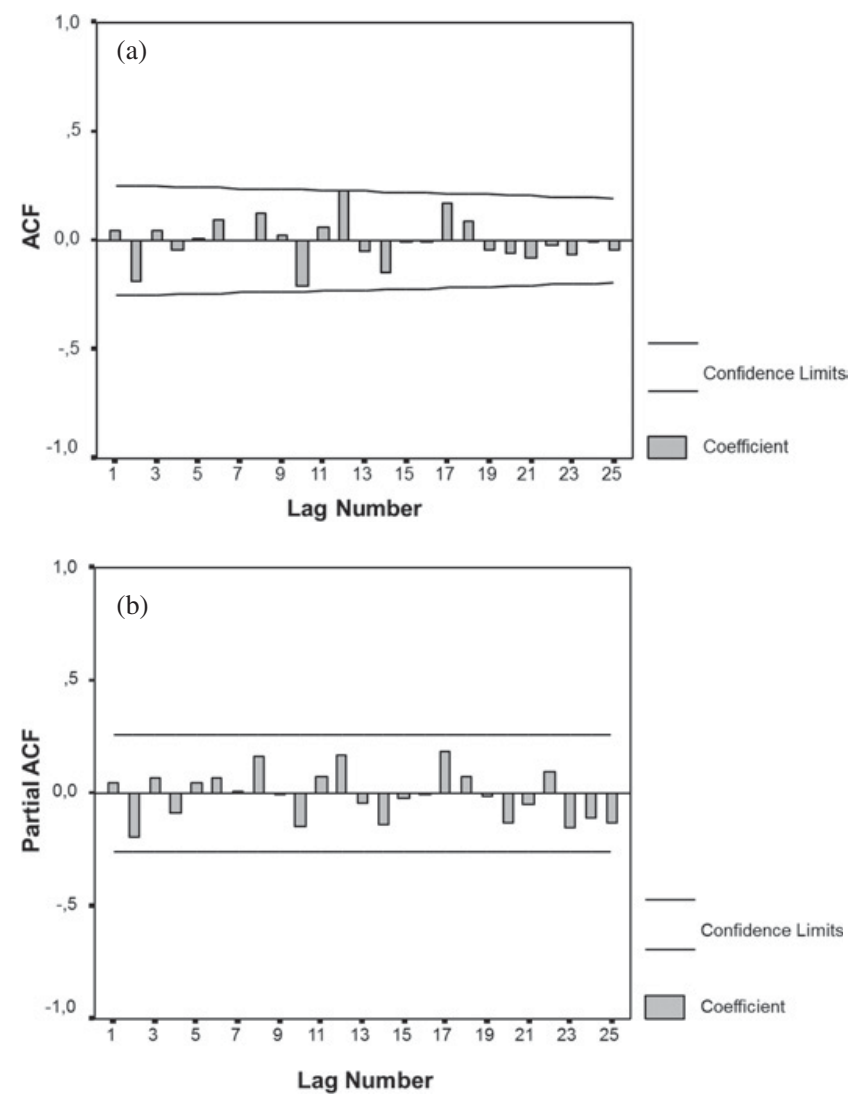

Fig. 6. (a) Simple autocorrelation of the residuals for the mean emergence of Trichoptera. (b) Partial autocorrelation of the residuals for the mean emergence of Trichoptera.

responds to water flow, to strategies such as short life cycles that allow fast population renewal, and to resistance mechanisms such as those found in the larvae of the genus Simuliidae, which have a sucker that allows them to control the friction caused by water velocity. It is also known that Simuliidae larvae and pupae are positively reophilic (Coscaron and Coscaron, 2007).

The emergence of Trichoptera was highest in the lowest discharge categories. The results of this study, which generally coincide with those of Wolf et al. (1988) and Flint and Masteller (1993), showed a drop in tricoptera emergences during peak rainfall (an environmental factor) and, to a lesser extent, at lower temperatures (a physical factor). These seem to be the limiting factors for emergence. The MA(I) model suggests that populations make a faster recovery due to their greater resistance to drag, which is achieved by the construction of capture nets and shelters that act as protective barriers against changes in water-flow volume (Margalef, 1994).

Model MA(II) suggests that in addition to environmental conditions, Ephemeroptera emergence may have been limited by the following biological factors: (1) recolonization by drift due to the loss of larger individuals by drag (Allan and Castillo, 2007); (2) recolonization of organisms from downstream areas (Turcotte and Harper, 

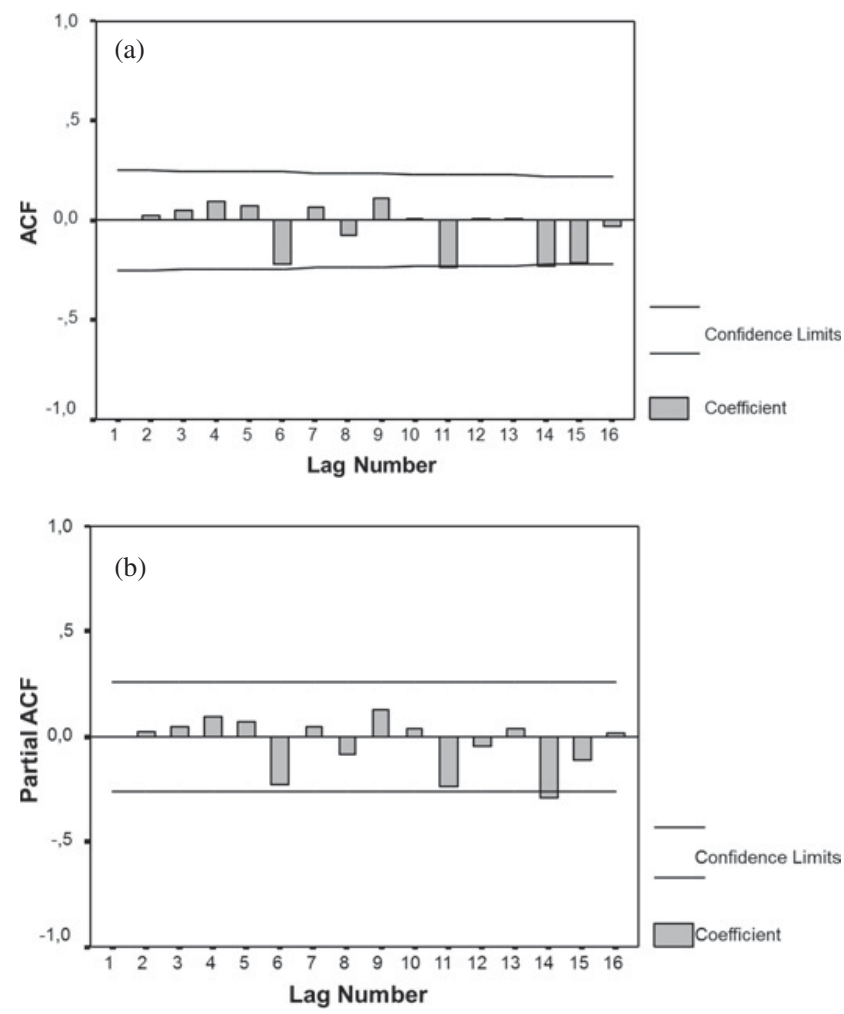

Fig. 7. (a) Simple autocorrelation of the residuals for the mean emergence of Ephemeroptera. (b) Partial autocorrelation of the residuals for the mean emergence of Ephemeroptera.

1982); (3) the population size of different nymph stages present in the study site (Pescador et al., 1993); and (4) the development, reproduction and survival rates of the populations of the study organisms (Wolf et al., 1988). These factors could serve as the impetus for a posteriori hypothesis to be tested in the future.

Temporal patterns in insect emergence demonstrate the role of seasonal differences in the hydrological regime of Andean rivers. At a reach scale, discharge frequency generates emergence peaks at different times of the year, which affects different organisms in different ways. In general, all groups in the study area emerged in the first four discharge categories, which indicate a high level of adaptation of these organisms to low and constant waterflow. Moreover, the sensitivity of ETD to changes in discharge regime shows that an increase in extreme hydrological events due to global climate change would have profound effects on the diversity of aquatic insects and, in particular, on the populations of Ephemeroptera and Trichoptera.

Acknowledgements. This study was supported by the Pontificia Universidad Javeriana and the Universidad Nacional de Colombia. The Castro Rebolledo family provided the best possible conditions for our fieldwork at Tota. We thank two anonymous referees who offered valuable comments on the manuscript. This paper is dedicated to Memory of the Professor Maria Eugenia Rincon.

\section{References}

Allan J. and Castillo M.M., 2007. Stream Ecology: Structure and Function of Running Waters, Springer, Dordrecht, $436 \mathrm{p}$.

APHA, 1998. Standard Methods for Examination of Water and Wastewater (19th edition), American Public Health Association, Washington, USA.

Box G.E.P. and Jenkins G.M., 1976. Time Series Analysis, Forecasting Control. Holden-Day, San Francisco, 575 p.

Brittain J.E., 1982. The biology of mayflies. Annu. Rev. Entomol., 27, 47-119.

Buitrago J., Rosas A. and Vergara I., 1987. Análisis de la estabilidad en un sector entre Iza y Cuítiva, Departamento de Boyacá, Trabajo de grado, Escuela de Ingeniería Geológica, Universidad Pedagógica y Tecnológica de Colombia, Sogamoso, Boyacá.

Coffman W.P. and de la Rosa C.L., 1998. Taxonomic composition and temporal organization of tropical and temperate species assemblages of lotic Chironomidae. J. Kans. Entomol. Soc., 71, 388-406.

Corbet P., 2004. Dragonflies: Behaviour and ecology of Odonata, Harley, Colchester, 820 p.

Coscaron S. and Coscaron C.L., 2007. Neotropical Simuliidae (Diptera: Insecta), Aquatic Biodiversity in Latin America, Vol 3. Pensoft Publishers, Sofia - Moscow, 685 p.

Domínguez E. and Fernández H.R., (eds.), 2009. Macroinvertebrados Bentónicos Sudamericanos (Sistemática y Biología), Fund, Miguel Lillo, Tucuman, 654 p.

Donato J., Abuhatab Y. and Sabater S., 2014. Epilithic biofilm metabolism during the high water flow period in an Andean neotropical stream. Hydrobiology, 728, 41-50.

Flint Jr. O.S. and Masteller E.C., 1993. Emergence composition and phenology Trichoptera from a tropical rainforest stream at El Verde Puerto Rico. J. Kans. Entomol. Soc., 66, $140-150$.

Harper M.P. and Peckarsky B.L., 2006. Emergence cues of a mayfly in a high altitude stream ecosystem: potencial response to climate change. Ecol. Appl., 16, 612-621.

Huhta A., Muotka T. and Tikkanen P., 2000. Nocturnal drift of mayfly nymphs as a post-contact antipredador mechanism. Freshwat. Biol., 45, 33-42.

IDEAM, 1998. El medio ambiente en Colombia, Instituto de Hidrología, Meteorología y Estudios Ambientales, $495 \mathrm{p}$.

IGAC, 1980. Instituto General de suelos de los municipios de Aquitania, Cuítiva, Mongui, Nobsa, Sogamoso, Tibasosa, Tópaga y Tota (departamento de Boyacá), 378 p.

Ivković M., Miliša M., Previšić A., Popijač A. and Zlatko M., 2013. Environmental control of emergence patterns: case study of changes in hourly and daily emergence of aquatic insects at constant and variable water temperature. Int. Rev. Hydrobiol., 98, 104-115.

Jacobsen D., 2005. Temporally variable macroinvertebrate stone relationships in streams. Hydrobiologia, 544, 201-214.

Jacobsen D., 2008. Tropical high-altitude streams. In: Dudgeon D. (ed.), Tropical stream ecology. Academic Press, San Diego, 219-256.

Lewis W.M., 2008. Physical and chemical features of tropical flowing waters. In: Dudgeon D. (ed.), Tropical Stream Ecology, Elsevier, London, 1-21. 
Margalef R., 1994. The place of epicontinental waters in global ecology. In: Margalef R. (ed.), Limnology now, A Paradigm of Planetary Problems, Elsevier Science, Amsterdam, $553 \mathrm{p}$.

Merritt R.W. and Cummins K.W., 1995. An Introduction to the Aquatic Insects of North America, Kendall Hunt Publishing Company, Dubuque, Iowa, 862 p.

Peckarsky B.L., Taylor B.W., McIntosh A.R., Mcleek M.A., and Lytle D.A., 2001. Variation in mayfly size at metamorphosis as a developmental response to risk of predation. Ecology, $82,740-757$.

Pescador M.L., Masteller E.C. and Buzby K.M., 1993. Composition and phenology of Ephemeroptera from a tropical rainforest stream at El Verde, Puerto Rico. J. Kans. Entomol. Soc., 66, 151-159.

Poepperl R., 2000. Benthic secondary production and biomass of insects emerging from a northern German temperate stream. Freshwat. Biol., 44, 199-211.

Sabater S., 2008. Climate and disturbances affecting rivers: From microbes to ecosystems. In: Valladares F., Camacho A., Elósegui A., Gracia A., Estrada M., Senar J.C. and Gili J.M., (eds.), Unity in Diversity: Reflections on ecology after the legacy of Ramon Margalef, Fundación BBVA, Bilbao, 55-81.

Schlesinger W.H., 2000. Biogeochemistry: An Analysis of Global Change, Ariel Ciencia, Barcelona, 577 p.

Siqueira T., Roque F de O. and Trivinho-Strixino S., 2008. Phenological patterns of neotropical lotic chironomids: is emergence constrained by environmental factors? Aust. Ecol., 33, 902-910.

Statzner B. and Resh V.H., 1993. Multiple-site and -year analyses of stream insect emergence: a test of ecological theory. Oecologia, 96, 65-79.

Turcotte P. and Harper P.P., 1982. The macro-invertebrate fauna of small Andean Stream. Freshwat. Biol., 12, 411-419.

Whiles M.T. and Goldowitz B.S., 2001. Hydrologic influences on insect emergence production from Central Platte River wetlands. Ecol. Appl., 11, 1829-1842.

Wolf M., Mathias V. and Roldán G., 1988. Estudio del desarrollo de los insectos acuáticos, su emergencia y ecología en tres ecosistemas diferentes en el departamento de Antioquia. Actualidades Biológicas, 17, 2-27. 